\title{
Making rights real in Bangladesh through collective citizen action
}

\author{
Simeen Mahmud
}

\section{Introduction}

Perceptions about expected roles of citizens, state and other actors in the development of a 'good society' indicate a significant change in the emerging meanings of citizenship in poor countries of the contemporary developing world (Commonwealth Foundation 1999). Particularly noteworthy is the shift from a concept of citizenship as a "national identity, which entitles one to a bundle of rights", prevalent in the established democracies of the West, to new forms of citizenship emphasizing the exercise of agency and the re-casting of rights by citizens themselves (Cornwall 2000). These perceptions are fuelled in large part by the 'rights based approach' to development, where exclusion itself is seen as a denial of rights. This approach calls for citizen participation and engagement in the identification and articulation of rights rather than for citizens to be merely the bearers of rights.

A number of elements in these new perceptions of citizenship are noteworthy. They include a universal adherence to the principles of democracy (the right to have a say in how one is governed and in one's shared future); recognition of legal personhood or absolute equality before the state (to have rights provided and protected by the state and not granted as privileges through patron-client relationships); a sense of identity (not only national but also as a member of the community with respect for culture, cooperation and sharing); and a sense of agency that is, the belief that one can be and act as a citizen, that people can define their own spaces for participation and their own 'entry points of change', that participation itself is a citizen right.

Collective citizen action can be a way of materialising rights in poor developing countries and of realising this new citizen role. In this paper collective citizen action is defined as the process of conscious and purposeful mobilization of people around a common or shared concern with the failure of provision and protection of existing rights. Collective action can also mobilise people around newly articulated rights, such as the right to land or to credit. Collective action is also the process of acquiring social and political space and the operational mechanism for making 'voices' heard in influencing the action of others. It promotes equality of personhood by protesting against unequal provision and protection of rights and by reducing extreme forms of dependence and strengthening the ability to exercise agency. It fosters a sense of citizen identity through a belief that one has the right to have rights as a member of the community. Finally, collective action generates civic agency and citizen competence through engagement and participation, not as individuals but as a group, against oppressive and exclusionary, but socially accepted, norms that render formal rights ineffective.

In the context of development collective action also has instrumental value, given its potential to increase the costeffectiveness of public service delivery. In the form of effective statecommunity alliances, collective action can tap local energy and resources to reduce the potential for elite capture and improve local public sector institutions and service delivery (Das Gupta et al. 2000). Asserting citizenship through participation in social provisioning can be a way of seeking greater accountability from public service providers (Cornwall and Gaventa 2000). 
This paper explores contemporary collective action in Bangladesh to see whether the process can contribute to greater citizen agency in articulating and claiming rights, leading to a relevant and more inclusive concept of citizenship. It reports initial findings from a number of case studies representing different forms of collective action - from public protest to comanagement of public services - in the health and education sectors. The analysis of these case studies focuses on social differentiation, the nature of alliances between different groups and the role of elites in the actions described, and the implications of these factors for inclusive citizenship.

\section{Citizenship and collective action in Bangladesh}

Although an allembracing notion of the citizen with certain absolute rights guaranteed by the state is recognized in the Bangladesh constitution, this is more in form than in reality. The meanings of citizenship at the level of people's lived realities are not well perceived and even less easily articulated and conveyed, and citizen rights are at best recognized as fragmented claims or privileges dependent upon the good intentions of powerful state, private and market agencies. There is, in fact, a culture of bestowing privileges and patronage rather than a culture of guaranteeing rights. Legal rights guaranteed by the state are frequently not recognized as legitimate, while socially legitimate claims and privileges are differentiated by gender and social status and are rarely all-inclusive ${ }^{1}$.

This absence of a 'culture of rights' in Bangladesh is perpetuated by structural constraints that prevent translation of formal rights, even narrowly defined, into real rights that are socially legitimate. These structures are supported by social norms that have traditionally generated much inequality and led to a tacit acceptance of considerable social injustice and social exclusion. Their effect in preventing the emergence of any meaningful definition of citizenship and rearticulation of state-citizen relationships can be traced to what Kabeer (2000), following Fraser, calls 'recognition' and 'resource' problems: lack of 'recognition' by state, market and community agencies of the rights and entitlements of citizens, and lack of 'resources' on the part of citizens to articulate, voice and demand their rights and entitlements.

Although poverty has been a major contributing factor in both 'recognition' and 'resource' constraints, it is not the only cause of exclusion in Bangladesh society. State policy and implementing agencies reinforce existing political, social and market structures of exclusion. As a result, rights are not articulated similarly for all people at all times and, even when articulated similarly, they are not provided equally.

The near absence of accountability of state and non-state agencies also leads to exclusion, since those in 'power' remain beyond the reach of those without power or 'voice'. Accountability is further eroded by global and donor pressure to increase dependence upon markets, which fail to function effectively due to inefficient regulation by state agencies. Thus, state and social/economic institutions, singly and in collusion, are formidable barriers to the articulation and the equal provisioning of rights to all. Furthermore, these institutions play an important role in establishing the language of rights and in creating dependency in the ability to exercise agency. 
Given people's exclusion from processes that define social, economic and political rights, collective citizen action can provide the space and opportunity for engaging in a process of 'making rights real'. In the past, oppression and injustice under customary laws of the land formed the basis for most collective actions. The history of collective action in Bangladesh is quite long, going back two centuries to the peasant uprisings against the zamindars (landlords) and the East India Company government. The most recent of these peasant uprisings was the "Tebhaga" movement of 1946. Since then, of course, the country has experienced the independence movement of 1971, a collective action of unprecedented proportions.

More recently, collective action has been less confrontational, and the notion of absolute rights guaranteed by the state and the related 'language' 2 of rights is now more easily articulated, possibly linked to the post-independence evolution of democratic processes in civil and political life, however weak and immature these may be. Social injustice is less in the forefront perhaps because formal commitment to rights is plentiful. However, the gap between commitment and reality is large and expanding, and forms the basis of collective citizen action today.

\section{Four case studies}

Both social and economic rights have been the focus of collective citizen action in Bangladesh. Actions have ranged from efforts to acquire the right to common property resources like khas (government) land and haors (bodies of water), to protests and attempts to seek redress for the violation of farmers' water rights by shrimp cultivators, for corruption in fertilizer dealership, for poor quality of public health services, for the absence of safety in the workplace, for police violence, for unlawful arrest, for delays in the distribution of school textbooks, for eviction of slum-dwellers, and so on. Generally, collective actions have been on the basis of alliances forged between affected groups and mediating organizations, and initiatives taken by marginalized groups on their own are rare.

The cases discussed in this paper represent collective actions for claiming rights and entitlements with respect to health and education. These sectors were chosen because inequalities in health and education have been just as persistent as inequalities in income, if not more so, and probably contribute more to social exclusion than income-poverty. The specific cases were selected because they represent different types of partnerships and alliances, between community groups, nongovernmental organizations (NGOs), local government representatives and state agencies. They include collective action to establish women's right to safe contraceptive services; to challenge state failure in the provision of school textbooks; to secure a more accountable public health service; and to establish community ownership of a public health facility.

These case studies were based on information collected from one-to-one interviews, unpublished internal documents, newspaper articles and direct observation of events including protests, committee meetings, and service provision. The data were collected during FebruaryMarch 2001. The analysis sought to examine the following aspects of group operation: identity of the partners in the alliance or group; group functions and rationale for mobilization; rules of operation including inclusion criteria, conflict resolution and ensuring consistency of action; and distribution of costs and benefits. The main issues for analysis were identity and inclusiveness, recognition of rights, tackling social differentiation and equity. 


\section{Case Study 1: The Family Planning Association}

The struggle to legitimize women's need for birth control within a socio-economic context that favours early childbearing and a preference for sons, and to convince the state to take responsibility for provision of modern contraceptive services, was initially taken up in 1950 by the Family Planning Association of Bangladesh (FPAB). The divergent interests focusing on the one hand on women's health needs and on the other on the national imperative to curb high population growth rates found a common meeting ground in the form of a family planning association whose message was "A small family is a happy family". By 1958 the Association had succeeded in convincing the government to initiate a national family planning programme, and in 1965 to incorporate contraceptive services into its mainstream health service. The FPAB continued to function on its own, however, by redefining its pioneering role to one of complementing government programmes. After the International Conference on Population and Development (ICPD) in 1994, the interests of the association were further broadened to include mainstreaming reproductive rights within the health service and establishing the need to place population programmes within a development context.

The FPAB achieved high visibility in policy-making fora by mobilizing elite volunteers ${ }^{3}$ to form the National Executive Committee, with the role of influencing policy. It achieved social relevance by recruiting the bulk of its volunteers at the local level. These volunteers, recruited from the educated rural youth, had the role of raising awareness within their respective communities about women's need for contraceptive services, creating social acceptability of the concept of family planning, and motivating willing couples to adopt birth control methods. The differentiation in membership, although operating in a highly hierarchical relationship, increased tremendously the outreach and local relevance of a collective action which was initially very elitist and whose leadership was socially removed from the lot of the people it wished to benefit. It also provided much needed political and economic clout. The fact that membership was voluntary, even entailing a membership fee, suggests that local youth had a strong interest in joining the action ${ }^{4}$.

\section{Case Study 2: The textbook protests}

In Bangladesh the provision of education is the responsibility of the state, although private schools also function within the mainstream education system. As part of this obligation school textbooks are made accessible to all students enrolled in the mainstream schooling system by providing subsidies. This is done by distributing books to primary students (grades 1-5) free of cost and by selling books at low cost to students in grades $6-9$ through designated dealers operating in the market.

In 2001 there was a large delay in the production and distribution of school textbooks. The delay was caused by a breach of the usual practice for awarding contracts for the printing, binding and distribution of the huge quantity of books ( 80 million) by the Ministry of Education ${ }^{5}$. The entire job was awarded to one firm despite the considerable risk this entailed, and despite the fact that the National Curriculum and Textbook Board (NCTB) had identified the risk in advance. Additionally, since the monopoly on production and distribution was enjoyed by the same organization, students were compelled to purchase notebooks produced by that firm when buying subsidized textbooks supplied by the NCTB. 
The delay in production was first reported by newspapers, and later picked up by several student organizations which issued press statements demanding clarification from the Ministry. Ultimately, the student wing of one left political party went on to further action, which included organizing public protest rallies in visible locations, mobilizing the school student community and presenting a memorandum to the Prime Minister demanding punishment of the relevant agencies within the Ministry. Students from some schools in Dhaka joined some of these activities, including the protest meetings.

The objective of the collective action was two-fold. The interest of the student organization was to expose the inefficiency and lack of accountability of government agencies, which they described as systemic and long-standing rather than random and one-off. The interest of the school students was apparently to have access to textbooks on time, but detailed interviews with participants revealed a more complex set of interests ${ }^{6}$. The relatio nship between the student organization and school students was extremely hierarchical, with the student organization providing leadership. Their role was to mobilize the school students for participation in the protest activities. The role of the school students was to lend credibility to the action by participating, which they did despite considerable anticipated costs in terms of the wrath of parents and punishment by school authorities. Maintaining consistency of action was relatively simple because of the hierarchical relationship and the strict inclusion criteria, which excluded guardians and school management.

\section{Case Study 3: Health Watch Committees}

The Bangladesh government has for sometime realized that state provision of health care does not meet the minimum standards of service quality and performance accountability, leading to extreme underutilisation of services. Although internal mechanisms of performance accountability of health professionals and service providers are in place these are nonfunctional. Moreover, since public health care is provided free of cost users are not in a position to demand high quality or responsible service ${ }^{7}$.

The Ministry of Health and Family Welfare (MoHFW) seeks to improve the quality of public health care and increase accountability of public service providers, but believes this will not be possible simply through strengthening internal mechanisms of accountability, and that direct monitoring from outside by users and other stakeholders will be a powerful tool that should also render mechanisms of internal accountability more efficient. The Ministry has turned to NGOs to help form health watch committees (HWCs) composed of local residents to monitor the performance of service providers at the thana (subdistrict) and union levels on an experimental basis in nine thanas. Thus, the HWC is a state-community alliance facilitated by an NGO.

The interest of the MoHFW is to ensure the delivery of accountable and good quality health care at the local level. The interest of the NGO is to mobilise the poor to claim good quality public health services. The interest of the community is to have a responsible and answerable public health service in the locality that maintains a minimum standard of quality and is accessible to all users, poor and non-poor. The role of HWC is to make users' claims more visible and relevant to service provision, and to make service providers answerable to users. 
Another role is to enable the poor to access services and exercise greater agency in demand ing good quality and accountable health service ${ }^{8}$.

The selection process of the HWC was conceived to be inclusive and democratic, with representation from all socio-economic classes in the community, including marginal groups like women and the landless. Although actual selection was by "popular voting", a detailed study of one HWC indicated that the process was strongly influenced by the NGO worker, causing membership to be biased against local elite and influential persons. This exclusion was not without cost, since there was an absence of participation in the HWC by local users who were not affiliated to the NGO and a lack of confidence in its ability to monitor provider performance ${ }^{9}$. Moreover, the lack of legal recognition of the HWC's mandate and insufficient official support in the form of a system of penalties and incentives linked to performance meant that service providers, especially health professionals, viewed the monitoring role of the HWC with considerable disregard and skepticism.

In the HWC which was the focus of the detailed study, the relationship between members was reciprocal and sharing of responsibility was democratic, with an elected president and the NGO worker officiating as secretary. However, absence of effective authority within the HWC meant that leadership was captured by the NGO worker. He derived power from being the HWC's link with the MoHFW ${ }^{10}$, and also because from his higher educational status and his close personal relationships with thana government officers, including health professionals. The NGO worker consolidated his leadership by recruiting as many HWC members as possible from members of his own NGO, whose support he could rely upon. Progress reports from other HWCs indicate that this pattern also applied more widely.

On the other hand, the HWC itself had no mechanism for monitoring the actions of the NGO worker to prevent activities that might undermine its role ${ }^{11}$. This limited the scope of the HWC's monitoring role, and its functions were confined to raising awareness about health concerns, enabling poor users to access services and motivating residents to use local facilities to a greater extent ${ }^{12}$. Anticipated reaction from government officers, whose social status was higher than that of the HWC members, lack of self-confidence among members and doubts expressed about their competence also helped to limit the monitoring role ${ }^{13}$.

\section{Case Study 4: Community Groups}

The provision of accessible essential health services to the most deprived population groups (women, children and the very poor) is a commitment of the Bangladesh government. The approach adopted by the MoHFW is to promote community ownership and management of a community based health facility providing a package of essential services (ESP) within easy access of local residents. It is believed that community ownership and easy accessibility will improve responsiveness of providers to the needs of the most vulnerable groups and increase their accountability to the users.

To this end, government decided to set up one-stop community clinics in every village/ward to deliver the ESP. These would be owned and managed by a community group (CG) composed of union parishad (local government body) representatives, local service providers and community representatives committed to social work and representing various professional groups and social classes. Community ownership would be ensured by building the clinic on 
land donated by the village and by having the community share costs of construction and operation of the clinic with government ${ }^{14}$.

The interest of the MOHFW was effective delivery of the ESP through community participation. The interest of local government was to have an active role in implementation of government programmes at the union level. The interest of the local community was to have a reliable and responsive health service that was accessible by the most vulnerable groups and answerable to the community ${ }^{15}$.

Although the CGs were supposed to be formed through broad-based consultation between local elected representatives, thana health professionals and community members, in the CG which was the focus of the detailed study the formation was quite selective, resulting in community representation being biased towards better-off professional classes ${ }^{16}$. The inclusion of elected union parishad members, including a woman, and locally posted health service providers increased the acceptability of the CG within the government machinery, but acceptability within the community appeared limited. While the Thana Health and Family Planning Officer (THFPO) provided medicines and other supplies from the thana Health Complex (which he was not formally obliged to do), the CG was not able to establish enough moral authority to allow them to raise funds from the community for clinic maintenance.

However, lack of official recognition from the MoHFW also contributed to the absence of authority and credibility of the CG, which constrained its functioning. Government officials at the thana and union levels, although supportive, were not inclined to delegate authority to the CG with regard to clinic management and would override decisions taken by the group ${ }^{17}$. The relationship between the CG members was not hierarchical, but one of mutual reciprocity and reliance. However, there was a lack of effective leadership and proper delineation of authority and responsibility within the $\mathrm{CG}^{18}$, which contributed to the group's inability to perform its role effectively.

\section{Emerging Lessons}

The experience of collective citizen action in making rights real in Bangladesh is mixed, and four case studies are by no means sufficient to draw strong conclusions. However, these cases have generated a number of insights, which will be further explored in relation to a wider range of cases in future research by the Bangladesh team of the Development Research Centre on Citizenship, Participation and Accountability.

\section{Social hierarchies}

Highly structured social and state institutions hindered spontaneous emergence of collective citizen action. Indeed, all four cases were actions induced by more powerful groups outside the community directly concerned. Unequal power sharing within the community constrained people's ability to recognise, articulate and claim rights and inhibited spontaneous action. The democratic space created and exercise of citizen agency was also difficult to sustain without broader power sharing within the society and without putting in place a system of provider incentives and penalties. 
However, the reproduction of power hierarchies within the group was utilised to overcome structural resource and recognition constraints. Socio-economic differentiation within the group actually enabled the emergence of effective leadership, while reciprocity and equality of group membership led to the absence of authority and proper delineation of responsibility ${ }^{19}$. Maintaining group discipline and consistency of action of partners was easier when group operation was hierarchical. When rules of group operation were flexible and lines of authority were not clear, the group became ineffective.

\section{Identity and inclusiveness}

Initial identities of partners were diverse and differentiated by class and power. The basis for action was not shared experience of exclusion and disadvantage, but rather divergent interests and varied experiences coming together in a common meeting ground for action. Hence, participation in collective action did not lead to an inclusive citizen identity, although in some cases engagement in citizen action and the experience of gaining social and political space for 'voice' and exercise of agency provided a new identity for the most disenfranchised, namely poor women. Participation also generated a sense of social prestige and self esteem for groups including unemployed rural youth and rural professionals.

When collective action was initiated by a powerful group in the interests of a relatively less powerful one the implicit concept of citizenship was more inclusive, since those with rights were struggling to establish the claims of those who were denied rights. Thus, partnerships in some citizen actions indicate that a more inclusive concept of the citizen can emerge under certain situations.

\section{Recognition of rights}

Recognition and articulation of rights that directly addressed people's basic needs, such as the rights to food, shelter, clothing, education and health, was explicit. Rights of a higher order that were removed from people's immediate needs, such as the right to have accountable state and market agencies, were not perceived as clearly. In some cases the right to demand accountability of agents and institutions that were considered more powerful than those involved in the collective action was not only less understood, but was even denied or negated. Consequently, the mechanism of using people's participation as a tool to ensure accountability was also not well perceived. Demanding answerability of state and non-state agencies from outside and below, or vertical accountability (Bellour and Newell 2000), was not seen as legitimate or feasible citizen behaviour because of the considerable anticipated cost of a conflict of interest with more powerful groups in society.

\section{Tackling structural constraints}

Recognition of the rights of the least powerful was easier to achieve in situations where collective action was initiated by a powerful group or where there was co-option, either of the media or of highly placed bureaucrats and public figures. The state-community alliances, however, despite being initiated by state agencies, failed to establish the legitimacy of users' claims to accountable public services because of their inability to establish their own credibility in representing users or the community. 
Resource constraints were more difficult to tackle. People's dependency in exercising agency was not only due to poverty, but also to the scarcity of resources needed for action, including access to networks and information, organizational skills, and resources to deal with 'anticipated reaction' from more powerful members of the community. Even alliances between state and community or partnerships involving powerful groups were not always sufficient to mobilise these resources.

\section{Equity}

Participation in collective action imposed burdens on the different partners, but costs were anticipated rather than actual. Anticipated costs were sometimes high enough to deter participation. At other times anticipated costs did not prevent participation but caused participation to be less than optimal, by leading participants to limit themselves to activities which did not involve direct engagement with conflicting interests. This contributed to the absence of a sense of agency and citizen competence. The real costs - those of time and effort were relatively small, and the voluntary nature of participation meant that costs were unlikely to be inequitable.

The nature and magnitude of benefits derived depended upon the motivation for participation. When direct self-interest was not the motivation benefits were small, consisting of enhanced self-esteem and social prestige. When participation was motivated by self-interest anticipated costs were large, and potential benefits were also likely to be large ${ }^{20}$. Hence, although benefits were not experienced equally, distribution of benefits among partners was not inequitable.

These insights from the initial case studies highlight a number of more widely-applicable emerging lessons, whose implications will be explored in further research Unequal power sharing within the community and fear of 'anticipated reaction' from more powerful groups limits space for action and spontaneous citizen agency. Consequently, collective action enables citizen agency in claiming rights that have direct bearing upon people's lived realities, but is less effective in enabling agency in claiming rights that involve a conflict of interest. Existing power hierarchies are often reproduced within groups engaged in collective action, and are even utilised for achieving group objectives. In fact, socio-economic differentiation rather than reciprocity and equality within the group was found to be more conducive to the emergence of effective leadership. Costs imposed by and benefits derived from participation in collective action depend upon the motivation for participation; in the case studies, these were found to be distributed quite equitably. The process of collective action is not itself sufficient to overcome social differentiation within the group and forge a common identity. Thus, the process of articulating and claiming rights takes place in a situation of continuing social differentiation, where inclusive citizenship remains an elusive concept. 


\section{References}

N Kabeer (2000) Inclusive Citizenship, (First Draft)

S Bellour and P Newell (2001) Mapping Accountability: Origins, Contexts and Implications for Development, (Draft).

H Z Rahman (2001) From "Voice” to "Influence": Giving Teeth to Participation, (Draft).

S Mahmud (2000) Informal Women's Groups in Rural Bangladesh: Group Operation and Outcomes, forthcoming in Group Behaviour and Development, (eds) Frances Stewart, Judith Heyer and Rosemary Thorpe, Oxford University Press.

S Mahmud (2001) An Anatomy of Collective Action in Bangladesh (Draft).

Commonwealth Foundation and CIVICUS (1999). Citizens and Governance, London: Commonwealth Foundation.

A Cornwall (2000). Beneficiary, Consumer, Citizen: Perspectives on Participation for Poverty Reduction, Stockholm, SIDA.

A Cornwall and J Gaventa (2000). From users and choosers to makers and shapers: Repositioning participation in social policy, IDS Working Paper 127, Sussex, Institute of Development Studies.

M DasGupta, H Grandvoinet and M Romani (2000?). State-Community Synergies in Development: Laying the basis for collective action, World Bank Policy Research Working Paper No. 2439, Washington, World Bank. 


\section{Notes}

${ }^{1}$ For example, it is accepted that the poor are not supposed to receive the same service as the non-poor or to be ensured the same degree of protection under law. At the family level women are not expected to have the same authority as men or to inherit or own property even though provided by law.

${ }^{2}$ In the case of the rights to food, clothing, shelter, education and health.

${ }^{3}$ Highly placed government officials, successful professionals and academics, respected social workers and health professionals.

${ }^{4}$ Sources: Interviews with FPAB Director and Assistant Director and FPAB internal documents at their office.

${ }^{5}$ The usual practice has been to award the job of printing, binding and distribution of textbooks to three different Associations, comprising numerous small firms of printers, binders and distributors.

${ }^{6}$ Informants said that they were motivated to join the protests because, although books were generally late every year, they were unusually late this year. Interviews also revealed that they also joined in because this was a novel and exciting experience for them and they would not be missed from school because of sporting and other non-academic events which take place in school during the first two months of the school year

${ }^{7}$ The poor quality of service allows the widespread collection of unofficial user fees.

${ }^{8}$ Sources: detailed interviews with NGO worker, thana level health and family planning officer, local users, local residents and elite, government and NGO documents on the health sector and monthly activity and progress reports prepared by local NGO offices for the MoHFW.

${ }^{9}$ Local residents and users of health facilities interviewed were unaware of the existence of the HWC, and expressed doubts about the effectiveness of a monitoring committee whose members lived far from the health facility. They also felt that the members were not qualified enough to question the activities of the doctors.

${ }^{10}$ He prepared the monthly reports to the donors and the Ministry.

${ }^{11}$ The NGO worker did not have to report on his activities as a member of the HWC. His friendship with the thana health and family planning officer (THFPO) may have undermined the monitoring capability of the HWC.

${ }^{12}$ Even when performance monitoring was actually attempted this was restricted to monitoring the cleanliness of facilities, rather than the professional and service performance of doctors and staff.

${ }^{13}$ The fact that members received only a day's orientation from the NGO contributed to their lack of confidence.

${ }^{14}$ The government provides a one-off grant for construction, personnel, equipment, stores and supplies and furniture. The community provides the land, supervision of construction, routine cleanliness and ma intenance of the clinic, security and management of service provision.

${ }^{15}$ Source: detailed interviews with CG members, health service providers at the CG, local elite and users and thana level health personnel.

16 The initiative came from a strongly motivated and influential local doctor and the CG was selected at a meeting convened by him. The land for the clinic was donated by his younger brother (who, however, was not very interested in this initiative).

${ }^{17}$ In one instance a local official ordered the community group to stop charging a fee of Tk.10 per family per month that was collected from users to raise funds for maintenance of the clinic. 
${ }^{18}$ The president of the CG was an exofficio position and his participation in the activities of the CG was hardly ever mentioned. He was also physically absent for a long period because of religious commitments

${ }^{19}$ Strong socio-economic hierarchies within the community are generally believed to undermine the potential for collective action (Das Gupta et al 2001).

${ }^{20}$ For example, for school students the benefit of timely access to textbooks would be quite significant, while the cost of being caught by school authorities or guardians would also have been severe. 